\title{
Clinical and Demographic Characteristics of Patients with COVID-19 Who Died in Modarres Hospital
}

\author{
Sara Besharat ${ }^{1}$, Nasser Malekpour Alamdari ${ }^{2}$, Nahid Dadashzadeh ${ }^{3}$, Ramin Talaie ${ }^{4}$, Seyed Shahram Mousavi ${ }^{3}$, \\ Abdolrazagh Barzegar ${ }^{3}$, Sasan Tavana ${ }^{5}$, Rohollah Valizadeh ${ }^{6,7}$, Mehdi Frouzesh $^{3 *}$ \\ ${ }^{1}$ Clinical Research and Development Center, Department of Radiology, Shahid Modarres Hospital, Shahid Beheshti University \\ of Medical Sciences, Tehran, Iran; ${ }^{2}$ Department of Surgery, Critical Care Quality Improvement Research Center at Shahid \\ Modarres Hospital, Shahid Beheshti University of Medical Sciences, Tehran, Iran; ${ }^{3}$ Department of Forensic Medicine, \\ Legal Medicine Research Center, Iranian Legal Medicine Organization, Tehran, Iran; ${ }^{4}$ Department of Gastroenterology and \\ Hepatology, School of Medicine, Shahid Modarres Hospital, Shahid Beheshti University of Medical Sciences, Tehran, Iran; \\ ${ }^{5}$ Department of Pulmonary Disease, School of Medicine, Shahid Modarres Hospital, Shahid Beheshti University of Medical \\ Sciences, Tehran, Iran; ${ }^{6}$ Department of Epidemiology, Student Research Committee, School of Public Health, Iran University \\ of Medical Sciences, Tehran, Iran
}

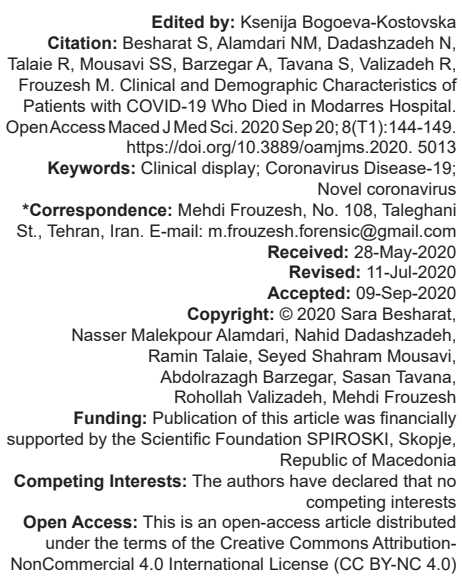

\section{Introduction}

Novel coronavirus (CoV) disease (COVID-19) is caused by severe acute respiratory syndrome (SARS)CoV2 and is a causative agent of a potentially lethal disease resulting in widespread concern in the global public health. $\mathrm{CoV}$ is one of the largest pathogens that mainly target the human respiratory tract. Previous outbreaks of CoV have included SARS and Middle East respiratory syndrome, which have long been known to be very threatening to public health. In late December 2019, a number of patients were admitted to hospitals whose initial diagnosis was a side effect of an unknown cause. The affected cases were associated with a wholesale market for seafood and wet animals in Wuhan, Hubei Province, China [1], [2]. Indeed, COVID-19 is a novel zoonotic disease caused by a novel
CoV that started from China and bat is the reservoir hosts of novel CoVs [3]. Epidemiological studies of primary cases of CoV pneumoniae-2019 showed that many cases were exposed to the seafood market in Wuhan, China [4]. The basic reproduction number of COVID-19 was reported from 2.24 to 3.58 [5].

The first official COVID-19 case in Iran was announced on February 19, 2020. On March 16, 2020, 4 weeks later, the daily situation report on COVID-19 showed about 5000 confirmed cases [6]. According to the World Health Organization (WHO), total confirmed cases of COVID-19 in Iran are 93,657 cases and show a decline slope so that in the last report, 80 deaths occurred on 30 April 2020 [7].

A study by Wang et al. showed that from January 10 to 24,2019 , the number of people infected 
with the novel coronavirus-2019 in China increased 31.4 times. They estimated the mortality rate of $2.84 \%$ for COVID-19. They also found that the male-to-female mortality ratio was 3.25 to 1 ; the median age of death was 75 years; the median time from the first symptoms to death was 14 days, and the median time from the initial symptoms to death in people aged 70 years and older (11 days) was shorter than people under 70 years (20 days) [8]. A study by Li et al. revealed that the mean age of 425 patients infected with novel CoV was 59 years, of which $56 \%$ were men; the mean incubation period was 5.2 days, and almost half of the adult patients were 60 years and older. The incubation period for COVID19 was 14 days after exposure, in which lots of cases occur approximately 4-5 days after exposure [9].

Detection of COVID-19 in most cases is not easy because most patients have mild or moderate syndrome with a strong prognosis. However, it may be necessary to identify an etiological factor in epidemiological studies, especially during epidemic outbreaks. Since the new CoV-2019 has not been found in humans before, no specific vaccine or treatment has been provided. Furthermore, drug therapy did not show optimum results in multiple organ failures [10], [11], [12], [13].

Renal involvement is prominent in this regard and it is recommended to check renal factors such as creatinine at admission [14], [15]. There is more need to conduct further studies in different conditions, for example, pregnant women, because the data of these conditions are sparse. Regarding that, many factors influence the development of any disease, special groups should be careful more [16], [17], [18], [19]. It is important to diagnose all suspected cases as soon as possible and to treat them quickly, to cut off the source of the infection. Conventional diagnostic testing methods, such as assessment to detect antiviral antibodies or viral antigens, have been clinically developed and used. New diagnostic solutions, including real-time polymerase chain reaction (RT-PCR) and microscopicbased measurements, may be effective in monitoring epidemiological measures, along with preventive measures [20], [21].

Like other CoVs, COVID-19 nucleic acids can be detected in samples such as nasopharyngeal swabs, sputum, lower respiratory tract secretions, blood, and feces. Clinical signs and graphic findings provide an acceptable diagnosis. It is showed that fever (78.9\%) and cough $(67.7 \%)$ were the most common symptoms. Diarrhea $(3.7 \%)$ and vomiting $(5 \%)$ were rare. Abnormalities in computed tomography (CT) images of the chest were observed in $96 \%$ of patients infected with novel CoV, and in $82.1 \%$ of them, lymphopenia was recorded [22]. In Italy and Bulgaria, the same clinical characteristics of COVID-19 were reported [23], [24], [25]. Furthermore, the mortality of the COVID-19 varies country by country and sometimes city by city [26], [27].

Due to the high mortality of COVID and the WHO's announcement of a pandemic on February
2020, further studies are needed to identify disease symptoms, prognosis, graphical, and paraclinical findings for definitive diagnosis and subsequent treatment. In this study, the clinical and demographic characteristics of the dead patients following COVID-19 development were evaluated.

\section{Methods}

In this descriptive-analytical cross-sectional study performed as a retrospective, the total numbers of patients died due to COVID-19 ( $n=62)$ were studied in Modarres Hospital, Tehran. The existing records of patients who died following COVID-19 were examined through census sampling and the variables of age, gender, body mass index (BMI), comorbidity, symptoms, liver profile, lipid profile, hemoglobin, platelet, white blood cell (WBC), lymphocytes, neutrophils, C-reaction protein (CRP), RT-PCR (for partial diagnosis), creatine phosphokinase (CPK), creatinine, blood urea nitrogen, potassium, magnesium, and sodium were examined.

Inclusion criteria were the patients with approved COVID-19 died within April 2020. Exclusion criterion was the illegible file of the patients. Indeed, the method of sampling was census. Regarding the case definition, the approved COVID-19 case was considered as a patient with a positive respiratory sample performed by PCR method (nasopharyngeal swab RT-PCR) with a sensitivity and specificity of $78.2 \%$ and $98.8 \%$, respectively [28]

There were 430 hospitalized patients at Modarres Hospital in April 2020, and 62 of whom died this month. The diagnosis was based on radiological chest X-ray, CT scan, PCR test, and initial symptoms of COVID-19 (evidence of extensive pulmonary involvement with tachycardia and respiratory rate above 25 or higher, fever, myalgia, and cough). $\mathrm{O}_{2}$ saturation was below $93 \%$, requiring hospitalization at the intensive care unit at the beginning of the visit or short-term after admission. These patients underwent treatment protocols based on the respiratory pattern and clinical findings and pulmonary scintigraphy in the middle and severe groups of COVID-19, including hydroxychloroquine with or without Kaletra $^{@}$ (Lopinavir+Ritonavir) and sometimes oseltamivir. Some patients were given antibiotics and corticosteroids, intravenous immunoglobulin, and Vitamin C ampoules. Depending on the patient's respiratory progression or progression of the disease to acute respiratory distress syndrome $\left(\mathrm{PiO}_{2} / \mathrm{FiO}_{2}\right.$ $<300$ ) or acute lung injury $\left(\mathrm{PiO}_{2} / \mathrm{FiO}_{2}<200\right)$, or suffering from respiratory distress or severe decrease of $\mathrm{O}_{2}$ saturation, they needed intubation and mechanical ventilation. 


\section{Statistical analysis}

Descriptive statistics (frequency, mean, and standard deviation) and analytical statistics were used to analyze the data analysis. All the analysis was conducted using SPSS. The Kolmogorov-Smirnov statistical test demonstrated that the data did not have a normal distribution. Thus, the nonparametric tests were used in order to analyze the data. $p<0.05$ was considered statistically significant.

\section{Ethical consideration}

This research was performed according to the Declaration of Helsinki. Informed written consent was obtained from the patients, and the study was approved by the Ethics Committee of Shahid Beheshti University of Medical Sciences (ethical code: IR.SBMU.RETECH. REC.1399.034, available at: http://ethics.research. ac.ir/IR.SBMU.RETECH.REC.1399.034).

\section{Results}

In this study, 62 patients who died due to confirmed COVID-19 in Modarres Hospital in Tehran. Regarding gender, $71 \%$ of patients were male and $69.4 \%$ had positive PCR test results, indicating low sensitivity of the test. Regarding age as an effective factor, $90.3 \%$ of patients had above 60 years old. Regarding lymphocytopenia, 56.5 of patients had lymphocytopenia. Indeed we used absolute lymphocyte count formula for calculating lymphocytopenia [29]. Thrombocytopenia is divided into three groups: mild $(100,000-150,000$ platelets/ $\mu \mathrm{L})$, moderate $(50,000-100,000$ platelets $\mu \mathrm{L})$, and sever $(<50,000$ platelets $/ \mu \mathrm{L})$ (Table 1$)$. In terms of clinical and paraclinical characteristics, patients had a mean BMI of $28.34 \mathrm{~kg} / \mathrm{m}^{2}$ (overweight class). The mean age was 67.62 years, with symptoms lasting 6.24 days, length

Table 1: The number of patients by lymphocytopenia, PCR, BMI, age, gender, and platelet patients with COVID-19

\begin{tabular}{lll}
\hline Variable & Number of patients & Percent \\
\hline Gender & 18 & \\
$\quad$ Female & 18 & 29.0 \\
$\quad$ Male & 44 & 71.0 \\
PCR test & & \\
$\quad$ Positive & 43 & 69.4 \\
$\quad$ Negative & 19 & 30.6 \\
Lymphocytopenia & & \\
Yes & 35 & 56.5 \\
No & 26 & 41.9 \\
BMI (kg/m ${ }^{2}$ ) & 7 & \\
$18.5-24.9$ & 15 & 22.6 \\
$25-29.9$ & 9 & 48.4 \\
$30-39.9$ & & 29.0 \\
Platelet (Count per mL) & 24 & 40.0 \\
$100-150$ & 8 & 13.3 \\
$50-100$ & 2 & 3.3 \\
$\quad<50$ & 1 & 1.6 \\
Age (year) & 5 & 8.1 \\
$28-40$ & 56 & 90.3 \\
$41-60$ & & \\
$>60$ & &
\end{tabular}

of hospital stay 6.64 days, and staying in the intensive care unit for 4.70 days. The mean serum creatinine and blood urea were $3.18 \mathrm{~g} / \mathrm{dl}$ and $125.9 \mathrm{mg} / \mathrm{dl}$, respectively, indicating renal involvement. Other laboratory variables are listed in Table 2. Regarding involvement of organs, $33.9 \%$ of patients had solely pulmonary involvement, which was often associated with cardiac involvement and systemic infection (17.7\%). However, all patients had pulmonary involvement accompanied by other organ involvements. In $16.16 \%$ of cases, pulmonary involvement was associated with renal involvement and

Table 2: Clinical and paraclinical characteristics of patients with COVID-19

\begin{tabular}{|c|c|c|c|c|c|}
\hline Variable & Minimum & Maximum & Mean & $\begin{array}{l}\text { Standard } \\
\text { deviation }\end{array}$ & Reference range \\
\hline Age (year) & 28.00 & 95.00 & 67.62 & 15.07 & - \\
\hline $\mathrm{BMI}\left(\mathrm{kg} / \mathrm{m}^{2}\right)$ & 21.40 & 39.50 & 28.34 & 4.13 & - \\
\hline $\begin{array}{l}\text { Duration of sign } \\
\text { (Day) }\end{array}$ & 1.00 & 20.00 & 6.24 & 4.14 & - \\
\hline $\begin{array}{l}\text { Duration of } \\
\text { admission sign (Day) }\end{array}$ & 1.00 & 20.00 & 6.48 & 4.64 & - \\
\hline $\begin{array}{l}\text { Stay in the intensive } \\
\text { care unit sign (Day) }\end{array}$ & 1.00 & 17.00 & 4.70 & 4.39 & - \\
\hline $\begin{array}{l}\text { Duration of } \\
\text { intubation sign (Day) }\end{array}$ & 1.00 & 17.00 & 4.34 & 4.25 & \\
\hline $\begin{array}{l}\text { WBC (Count per } \\
\text { microliter) }\end{array}$ & 2,700 & 177,000 & 15,470 & 22,330 & $4500-11,000$ \\
\hline $\begin{array}{l}\text { Lym (Count per } \\
\text { microliter) }\end{array}$ & 2,800 & 90,000 & 11,610 & 15,460 & $800-5000$ \\
\hline $\begin{array}{l}\text { Neut (Count per } \\
\text { microliter) }\end{array}$ & 5,900 & 96,000 & 82,260 & 18,070 & $5000-10,000$ \\
\hline $\begin{array}{l}\text { Plt (Count per } \\
\text { microliter) }\end{array}$ & 22,000 & 249,0000 & 208,230 & 312,130 & $150,000-450,000$ \\
\hline $\mathrm{Hb}(\mathrm{mg} / \mathrm{dl})$ & 6.60 & 128.00 & 15.52 & 20.64 & $\begin{array}{l}\text { Male: } 13.5-17.5 \\
\text { Female: } 12-15.5\end{array}$ \\
\hline CRP (mg/L) & 1.00 & 3.00 & 2.32 & 0.70 & $<10$ \\
\hline AST (mg/dl) & 27.00 & 4680.00 & 237.10 & 715.77 & $8-48$ \\
\hline ALT (mg/dl) & 21.00 & 2800.00 & 146.78 & 393.07 & $7-55$ \\
\hline $\operatorname{ALP}(\mathrm{mg} / \mathrm{dl})$ & 91.00 & 453.00 & 217.21 & 91.25 & $40-129$ \\
\hline Urea (mg/dl) & 31.00 & 370.00 & 125.96 & 84.31 & $7-20$ \\
\hline Creatinine (mg/dl) & 0.96 & 14.80 & 3.18 & 2.94 & $0.84-1.21$ \\
\hline $\mathrm{LDH}(\mathrm{U} / \mathrm{L})$ & 2.50 & 3408.00 & 1167.65 & 681.31 & $140-280$ \\
\hline CPK (mcg/L) & 33.00 & 1507.00 & 459.65 & 387.01 & $10-120$ \\
\hline $\mathrm{SpO}_{2}(\%)$ & 50.00 & 92.50 & 78.62 & 8.59 & $95-100$ \\
\hline
\end{tabular}

ALT: Aspartate aminotransferase.

11 patients undergone hemodialysis and 18 patients developed acute kidney injury. One person developed meningoencephalitis (Table 3 ). Regarding comorbidities, $24.4 \%$ of patients had hypertension and heart disease. Some affected patients had diabetes, gastrointestinal diseases, and cancer (Table 4). Regarding symptoms, $19 \%$ of patients had fever, cough, and shortness of breath together. However, $72 \%$ of patients showed fever. Some affected patients had diarrhea, lethargy, and fatigue (Table 5). A comparison of comorbidities by gender showed no significant differences (Table 6). In patients more than 60 years, the frequency of organ failures was significantly different and 10 patients were involved with renal failure, 13 patients with heart disease, and six patients with systematic infection. Approximately

Table 3: The number of organs affected following novel coronavirus infection

\begin{tabular}{lll}
\hline Involved organ & Number of patients & Percent \\
Lung & 21 & 33.9 \\
Lung and kidney & 10 & 16.1 \\
Lung, systematic infection & 5 & 8.1 \\
Lung, kidney, and systematic infection & 4 & 6.5 \\
Lung, systematic infection and heart & 11 & 17.7 \\
Lung, kidney, and heart & 5 & 8.1 \\
Lung, kidney, heart, and systematic infection & 4 & 6.5 \\
Lung and heart & 2 & 3.2 \\
Total & 62 & 100.0 \\
\hline
\end{tabular}


Table 4: The number of comorbidities in patients with COVID-19

\begin{tabular}{lll}
\hline Comorbidity & Number of patients & Percent \\
\hline Hypertension & 5 & 11.1 \\
Heart & 4 & 8.9 \\
Diabetes & 3 & 6.7 \\
Gastrointestinal & 2 & 4.4 \\
Cancer & 6 & 13.3 \\
Heart and diabetes & 6 & 13.3 \\
Heart and gastrointestinal & 2 & 4.4 \\
Hypertension and heart & 11 & 24.4 \\
Hypertension and diabetes & 3 & 6.7 \\
Hypertension and cancer & 1 & 2.2 \\
History of surgery & 1 & 2.2 \\
Cerebrovascular accident & 1 & 2.2 \\
\hline
\end{tabular}

all patients were involved with pulmonary disease (Table 7). Table 8 presents some predictive factors increasing the chance of mortality following COVID19 including shortness of breath (odds ratio: 1.821, p: 0.011 ), age more than 60 years (odds ratio: 4.022 ,

Table 5: The number of symptoms in patients with COVID-19

\begin{tabular}{lll}
\hline Symptoms & Number of patients & Percent \\
\hline Fever & 1 & 1.6 \\
Cough & 2 & 3.3 \\
Shortness of breath & 8 & 13.1 \\
Diarrhea & 1 & 1.6 \\
Fatigue & 3 & 4.9 \\
Lethargy & 1 & 1.6 \\
Fever and shortness of breath & 10 & 16.4 \\
Fever, cough, and shortness of breath & 19 & 31.1 \\
Fever and lethargy & 1 & 1.6 \\
Diarrhea, cough, and shortness of breath & 2 & 3.3 \\
Fever, cough, and lethargy & 3 & 4.9 \\
Fever, shortness of breath, and fatigue & 10 & 16.4 \\
\hline
\end{tabular}

p: 0.001), hypertension (odds ratio: 1.944, p: 0.036), diabetes (odds ratio: 2.085, p: 0.002), and cancer (odds ratio: 3.902 , p: 0.012). The results of multiple regression showed that age can be one of the main predictive factors. It should be noted that other factors were not significant in univariate regression.

Table 6: Comparison of comorbidities by gender

\begin{tabular}{llll}
\hline Comorbidity & \multicolumn{2}{l}{ Gender $(\%)$} & \multirow{2}{*}{ Statistics } \\
\cline { 2 - 3 } & Female & Male & \\
\hline Hypertension & $1(7.1)$ & $4(12.9)$ & \multirow{2}{*}{ X2 Fisher = 10.769 p = 0.444 } \\
Heart & $2(14.3)$ & $2(6.5)$ & \\
Diabetes & $1(7.1)$ & $2(6.5)$ & \\
Gastrointestinal & $0(0)$ & $2(6.5)$ & \\
Cancer & $0(0)$ & $6(19.4)$ & \\
Heart and diabetes & $2(14.3)$ & $4(12.9)$ & \\
Heart and gastrointestinal & $0(0)$ & $2(6.5)$ & \\
Hypertension and heart & $6(42.9)$ & $5(16.1)$ & \\
Hypertension and diabetes & $2(14.3)$ & $1(3.2)$ & \\
Hypertension and cancer & $0(0)$ & $1(3.2)$ & \\
History of surgery & $0(0)$ & $1(3.2)$ & \\
Cerebrovascular accident & $0(0)$ & $1(3.2)$ & \\
\hline
\end{tabular}

\section{Discussion}

Due to the emergence of COVID and the WHO's announcement of a pandemic in and finally, the need for identifying the clinical and demographic characteristics of COVID-19, we conducted this study. In summary, our study showed that among 62 dead people due to COVID-19, $71 \%$ of patients were male and $69.4 \%$ had positive PCR test results, indicating low sensitivity of the test; $90.3 \%$ of patients had above 60 years old; 56.5 of patients had lymphocytopenia;
Table 7: The number of organ failures in patients with COVID-19

\begin{tabular}{lllll}
\hline Organ & $\begin{array}{l}\text { Age more } \\
\text { than } 60 \text { years }\end{array}$ & $\begin{array}{l}\text { Age less than } \\
60 \text { years }\end{array}$ & p-value & $X^{2}$ \\
\hline Lung & 17 & 4 & 0.018 & 16.956 \\
Lung and kidney & 10 & 0 & & \\
Lung + systematic infection & 4 & 5 & & \\
Lung and kidney + systematic & 4 & 0 & & \\
infection & & & & \\
Lung + systematic infection + heart & 9 & 2 & & \\
Lung and kidney +heart & 4 & 1 & & \\
Lung and heart & 0 & 2 & & \\
\hline
\end{tabular}

the mean age was 67.62 years; with symptoms lasting 6.24 days. The mean serum creatinine and blood urea were $3.18 \mathrm{~g} / \mathrm{dl}$ and $125.9 \mathrm{mg} / \mathrm{dl}$, respectively, indicating renal involvement. All patients had pulmonary involvement accompanied by other organ involvements. Regarding symptoms, $19 \%$ of patients had fever, cough, and shortness of breath together. However, $72 \%$ of patients showed fever. Some affected patients had diarrhea, lethargy, and fatigue. A comparison of comorbidities by gender showed no significant differences. Regarding age, the frequency of patients died following COVID-19 $<60$ was low and it

Table 8: Logistic regression to predict the binary outcome (death following COVID-19)

\begin{tabular}{lllllll}
\hline Variable & $\mathrm{B}$ & $\mathrm{SE}$ & $\mathrm{p}$-value & Odds ratio & \multicolumn{2}{l}{$95 \% \mathrm{Cl}$} \\
\cline { 6 - 7 } & & & & & Lower & Upper \\
\hline Shortness of breath & 0.599 & 0.140 & 0.011 & 1.821 & 1.112 & 1.928 \\
HB & -0.994 & 1.011 & 0.098 & 0.370 & 0.211 & 2.344 \\
LDH & -1.084 & 1.141 & 0.599 & 0.338 & 0.138 & 12.112 \\
Neut & 0.0009 & 0.411 & 0.813 & 1.001 & 0.872 & 4.371 \\
Lymph & 0.207 & 1.057 & 0.342 & 1.230 & 0.239 & 15.091 \\
Cough & 1.099 & 0.982 & 0.067 & 3.003 & 0.919 & 43.310 \\
Age more than 60 years & 1.391 & 0.156 & 0.001 & 4.022 & 2.471 & 4.560 \\
Hypertension & 0.664 & 0.131 & 0.036 & 1.944 & 1.331 & 2.229 \\
Diabetes & 0.734 & 0.027 & 0.002 & 2.085 & 1.989 & 2.215 \\
Cancer & 1.361 & 0.141 & 0.012 & 3.902 & 2.656 & 4.625 \\
\hline
\end{tabular}

makes bias in interpretation. We should know that the majority of our study population consisted of patients who were above 60 years and this finding should not ignore the risk of mortality in younger patients. It is declared that some groups of people are more prone to develop COVID-19, including pregnant women and elderlies, in which older people are predisposed to this disease (age $>55$ years) [30]. The median age of patients with COVID-19 in a study by Richardson et al. was 63 years and $39.7 \%$ were female, while these results were consistent with our results [31].

Huang et al. found that $98 \%$ of patients with COVID-19 had a fever. They reported that patients referred with cough $(76 \%)$, fatigue and muscle pain $(44 \%)$, dyspnea $(55 \%)$, sputum expectoration $(28 \%)$, headache $(8 \%)$, hemoptysis $(5 \%)$, and diarrhea $(3 \%)$. Laboratory tests showed that $25 \%$ of infected patients had leukopenia and $64 \%$ had lymphocytopenia. Aspartate aminotransferase levels are elevated in $37 \%$ of patients. Myocarditis was diagnosed in $12 \%$ of patients, and very sensitive troponin I levels were significantly increased in these patients. Abnormalities in chest CT images were observed in $100 \%$ of patients [32]. According to Table 7, our study declared that COVID-19 is a multi-organ disease; in such a way 
that single-organ failure (lung) was shown in just 21 patients. In 10 patients, lung and kidney were involved together. Renal involvement was detected in 18 patients, accompanied by lung and heart involvement.

In a study entitled "Presenting characteristics, comorbidities, and outcomes among 5700 patients hospitalized with COVID-19 in the New York City area" done by Richardson et al., the results indicated $3.2 \%$ of patients were treated by renal dialysis. Richardson et al. reported hypertension as the most common comorbidity consistent with our study because heart disease, especially hypertension, was observed a lot in patients [31].

Zhao et al. revealed that Asian men were more likely to develop CoV infection in 2019 [5]. Guan et al. reported 1099 cases of the new CoV-2019 infection. They found that fever $(78.9 \%)$ and cough $(67.7 \%)$ were the most common symptoms. Diarrhea (3.7\%) and vomiting (5\%) were rare. Abnormalities in CT images of the chest were observed in $96 \%$ of patients infected with COVID-19, and in $82.1 \%$ of them, lymphopenia was recorded [22]. These results were consistent with our results. Approximately the reported symptoms and organ failure were recorded for the dead cases. There were no notable differences between the reviewed studies and the results of our study. The display of COVID-19 in Asian people is the same. While in a study by Richardson et al., 30.7\% was febrile, that's why the display of symptoms can be changed by geographical differences [31]. Our study found more fertile patients compared to the Richarson et al. study.

\section{Conclusion}

According to our results, the majority of died people affected by COVID-19 were overweight and more than 60 years old. In people who were more than 60 years, multi-organ failure was notable. Fever, cough, and shortness of breath were dominant symptoms like other studies but neurological complications following COVID-19 as meningoencephalitis is possible that can be used as a differential diagnosis. COVID-19 in people more than 60 years rings a dreadful bell to medical staff. Lung is always involved in both genders. We did not found differences between male and female regarding comorbidity, symptoms, and mortality rate.

\section{Acknowledgments}

We would like to thank the Vice-Chancellor for Research and Technology of Shahid Beheshti University of Medical Sciences and also the director of Modarres Hospital in Tehran Province for their cooperation in conducting this research (ethical code: IR.SBMU.RETECH.REC.1399.034).

\section{References}

1. Bogoch II, Watts A, Thomas-Bachli A, Huber C, Kraemer MU, Khan K. Pneumonia of unknown aetiology in Wuhan, China: Potential for international spread via commercial air travel. J Travel Med. 2020;27(2):taaa008. https://doi.org/10.1093/jtm/ taaa008

PMid:31943059

2. Lu H, Stratton CW, Tang YW. Outbreak of pneumonia of unknown etiology in Wuhan, China: The mystery and the miracle. J Med Virol. 2020;92(4):401-2. https://doi.org/10.1002/jmv.25678 PMid:31950516

3. Mackenzie JS, Smith DW. COVID-19: A novel zoonotic disease caused by a coronavirus from China: What we know and what we don't. Microbiol Aust. 2020;41:MA20013. https://doi. org/10.1071/ma20013

PMid:32226946

4. Wu F, Zhao S, Yu B, Chen YM, Wang W, Song ZG, et al. A new coronavirus associated with human respiratory disease in China. Nature. 2020;579(7798):265-9.

PMid:32015508

5. Zhao S, Lin Q, Ran J, Musa SS, Yang G, Wang W, et al. Preliminary estimation of the basic reproduction number of novel coronavirus (2019-nCoV) in China, from 2019 to 2020: A datadriven analysis in the early phase of the outbreak. Int $\mathrm{J}$ Infect Dis. 2020;92:214-7. https://doi.org/10.1101/2020.01.23.916395 PMid:32007643

6. Iranian Ministry of Health and Medical Education (MOHME); 2020. Available from: http://www.corona.behdasht.gov.ir/files/ site1/files/Factsheet_4._26.12_-_En.pdf. [Last accessed on 2020 Apr 15].

7. World Health Organization. Coronavirus Disease 2019 (COVID19) Situation Report-101. Geneva: World Health Organization; 2020. Available from: https://www.who.int/docs/default-source/ coronaviruse/situation-reports/20200430-sitrep-101-covid-19. pdf?sfvrsn=2ba4e093_2. [Last accessed on 2020 Apr 30]. https://doi.org/10.1016/j.disamonth.2020.101068

8. Wang W, Tang J, Wei F. Updated understanding of the outbreak of 2019 novel coronavirus (2019-nCoV) in Wuhan, China. J Med Virol. 2020;92(4):441-7. https://doi.org/10.1002/jmv.25689 PMid:31994742

9. Li Q, Guan X, Wu P, Wang X, Zhou L, Tong Y, et al. Early transmission dynamics in Wuhan, China, of novel coronavirusinfected pneumonia. N Engl J Med. 2020;382(13):1199-207. PMid:31995857

10. Valizadeh R, Baradaran A, Mirzazadeh A, Bhaskar LV. Coronavirus-nephropathy; renal involvement in COVID-19. J Renal Inj Prev. 2020;9(2):e18. https://doi.org/10.34172/ jrip. 2020.18

11. Dadashzadeh N, Farshid S, Valizadeh R, Nanbakhsh M, Rahimi MM. Acute respiratory distress syndrome in COVID-19 disease. Immunopathol Persa. 2020;6(2):e16. https://doi. org/10.34172/ipp.2020.16

12. Valizadeh $\mathrm{R}$, Dadashzadeh $\mathrm{N}$, Zakeri $\mathrm{R}$, James Kellner $\mathrm{S}$, Rahimi MM. Drug therapy in hospitalized patients with very severe symptoms following COVID-19. J Nephropharmacol. 2020;9(2):e21. https://doi.org/10.34172/npj.2020.21

13. Mubarak M, Nasri N. COVID-19 nephropathy; an emerging 
condition caused by novel coronavirus infection. J Nephropathol. 2020;9(3):e21. https://doi.org/10.34172/jnp.2020.21

14. Lotfi B, Farshid S, Dadashzadeh N, Valizadeh R, Rahimi MM. Is coronavirus disease 2019 (COVID-19) associated with renal involvement? Areview of century infection. Jundishapur J Microbiol. 2020;13(4):e102899. https://doi.org/10.5812/jjm.102899

15. Fortarezza F, Pezzuto F. COVID-19 nephropathy: What could pathologist say? J Nephropathol. 2020;9(4):e32. https://doi. org/10.34172/jnp.2020.32

16. Rasmussen SA, Smulian JC, Lednicky JA, Wen TS, Jamieson DJ. Coronavirus disease 2019 (COVID-19) and pregnancy: What obstetricians need to know. Am J Obstet Gynecol. 2020;222:415-26. https://doi.org/10.1016/j.ajog.2020.02.017 PMid:32105680

17. Dolatian M, Mahmoodi Z, Alavi-Majd H, Moafi F, Ghorbani M, Mirabzadeh A. Psychosocial factors in pregnancy and birthweight: Path analysis. J Obstet Gynaecol Res. 2016;42(7):822-30. https://doi.org/10.1111/jog.12991 PMid:27098096

18. Mahmoodi Z, Karimlou M, Sajjadi H, Dejman M, Vameghi M. Development of mother's lifestyle scale during pregnancy with an approach to social determinants of health. Glob J Health Sci. 2013;5(3):208-19. https://doi.org/10.5539/gjhs.v5n3p208 PMid:23618491

19. Dolatian M, Mirabzadeh A, Forouzan AS, Sajjadi H, Alavimajd H, Mahmoodi $Z$, et al. Relationship between structural and intermediary determinants of health and preterm delivery. $J$ Reprod Infertil. 2014;15(2):78-86.

PMid:24918080

20. Ghelichi-Ghojogh M, Allah Kalteh E, Fararooei M. Coronavirus disease 2019; epidemiology and recommendations. J Prev Epidemiol. 2020;5(1):e01. https://doi.org/10.34172/jpe.2020.01

21. Forouzesh $M$, Rahimi $A$, Valizadeh $R$, Dadashzadeh $N$, Mirzazadeh A. Clinical display, diagnostics and genetic implication of novel coronavirus (COVID-19) epidemic. Eur Rev Med Pharmacol Sci. 2020;24(8):4607-15. PMid:32374001

22. Fu L, Wang $B$, Yuan $\mathrm{T}$, Chen $\mathrm{X}$, Ao $\mathrm{Y}$, Fitzpatrick $\mathrm{T}$, et al. Clinical characteristics of coronavirus disease 2019 (COVID$19)$ in China: A systematic review and meta-analysis. J Infect. 2020;80(6):656-65.

PMid:32283155

23. Colaneri M, Sacchi P, Zuccaro V, Biscarini S, Sachs M, Roda S, et al. Clinical characteristics of coronavirus disease (COVID-19) early findings from a teaching hospital in Pavia, North Italy, 21 to 28 February 2020. Euro Surveill. 2020;25(16):2000460. https:// doi.org/10.2807/1560-7917.es.2020.25.16.2000460 PMid:32347201

24. Baymakova M, Popov GT. COVID-19: A review of part of the international experience. Med Rev (Sofia). 2020;56(3):5-13.

25. Grasselli G, Zangrillo A, Zanella A, Antonelli M, Cabrini L, Castelli A, et al. Baseline characteristics and outcomes of 1591 patients infected with SARS-CoV-2 admitted to ICUs of the Lombardy region, Italy. JAMA. 2020;323(16):1574-81. https:// doi.org/10.1001/jama.2020.5394

PMid:32250385

26. Daneshfar M, Dadashzadeh N, Ahmadpour M, Ragati Haghi H, Rahmani $\mathrm{V}$, Forouzesh $\mathrm{M}$, et al. Lessons of mortality following COVID-19 epidemic in the United States especially in the geriatrics. J Nephropharmacol. 2021;10(1):e06. https://doi. org/10.34172/npj.2021.06

27. Jahromi $A H$, Mahmoudi $H$. Real estimates of mortality following COVID-19 infection; an oversimplification of a complex issue. J Prev Epidemiol. 2020;5(1):e04. https://doi.org/10.34172/ jpe.2020.04

28. Jiang G, Ren X, Liu Y, Chen H, Liu W, Guo Z, et al. Application and Optimization of RT-PCR in Diagnosis of SARS-CoV-2 Infection. New York: medRxiv; 2020. Available from: https:// www.medrxiv.org/content/10.1101/2020.02.25.20027755v2. [Last accessed on 2020 Mar 22].

29. Ritter $S$. The absolute lymphocyte count (ALC) is a significant clue for immune deficiency. J Allergy Clin Immunol. 2019;143(2):AB115. https://doi.org/10.1016/j.jaci.2018.12.348

30. $\mathrm{Xu} X \mathrm{XW}, \mathrm{Wu} X X$, Jiang $\mathrm{XG}, \mathrm{Xu} \mathrm{KJ}$, Ying LJ, Ma CL, et al. Clinical findings in a group of patients infected with the 2019 novel coronavirus (SARS-Cov-2) outside of Wuhan, China: Retrospective case series. BMJ. 2020;368:m792. https://doi. org/10.1136/bmj.m792 PMid:32075786

31. Richardson S, Hirsch JS, Narasimhan M, Crawford JM, McGinn T, Davidson KW, et al. Presenting characteristics, comorbidities, and outcomes among 5700 patients hospitalized with Covid-19 in the New York City Area. JAMA. 2020;323(20):2052-9. https:// doi.org/10.1001/jama.2020.6775

PMid:32320003

32. Huang $\mathrm{C}$, Wang $\mathrm{Y}$, Li X, Ren L, Zhao J, Hu Y, et al. Clinical features of patients infected with 2019 novel coronavirus in Wuhan, China. Lancet. 2020;395(10223):497-506. https://doi. org/10.1016/s0140-6736(20)30183-5 